\title{
Research on the Method of Ideological and Political Integration of Artificial Intelligence Course
}

\author{
Haibo $\mathrm{Yi}^{1, *}$, Meng Xiao ${ }^{2}$ \\ ${ }^{1}$ School of Artificial Intelligence, Shenzhen Polytechnic, Shenzhen, Guangdong, 518055, China. \\ ${ }^{2}$ School of Management, Shenzhen Polytechnic, Shenzhen, Guangdong, 518055, China.
}

\begin{abstract}
How to cite this paper: Haibo Yi, Meng Xiao. (2021). Research on the Method of Ideological and Political Integration of Artificial Intelligence Course. The Educational Review, USA, 5(7), 204-207. DOI: 10.26855/er.2021.07.003
\end{abstract}

Received: June 22, 2021

Accepted: July 16, 2021

Published: July 23, 2021

Corresponding author: Haibo Yi, School of Artificial Intelligence, Shenzhen Polytechnic, Shenzhen, Guangdong, 518055, China.

Email: haiboyi@126.com

\begin{abstract}
Curriculum ideological and political education is one of the implementation methods of moral education. The main content of this paper is to integrate ideological and political education into artificial intelligence courses. Face recognition belongs to the teaching unit of the project cloud monitoring application development in the course of cloud application development. Taking face recognition task of artificial intelligence courses as an example, this paper introduces how to integrate ideological and political education into artificial intelligence course. Based on the learning task of face recognition, combined with the national and world conditions of epidemic prevention and anti-epidemic, the learning task of wearing face mask is increased, so that students from the class can understand the importance of epidemic prevention and enhance the sense of responsibility of science and technology to serve the society. The case in this paper can be used as a typical application of ideological and political education and moral education.
\end{abstract}

\section{Keywords}

Artificial Intelligence Course, Ideological and Political Integration, Vocational education, Moral Education

\section{Introduction}

Ideological and political education of curriculum refers to a comprehensive education concept which takes "moral education" as the fundamental task of education by building a pattern of all staff, the whole process and the whole curriculum education, forming a synergistic effect between all kinds of courses and ideological and political theory courses (Ali, 2020; Chan, 2019; Liu, 2019; Lu \& Xunzi, 2020; Mapana, 2020; Mukhlas \& Fajriani, 2020; Park, Noh, \& Jeong, 2020; Yan \& Slattery, 2021; Zulafiat, 2019; Zybaa, 2021).

"Face recognition-wearing a mask for you" belongs to the teaching unit of the project "cloud monitoring application development" in the course of cloud application development. It is based on the two international standards of cloud computing promoted by China, with reference to the national planning textbook, the $1+\mathrm{X}$ certificate textbook of higher vocational education and the new loose leaf handout independently developed, combined with the talent training program and the content of cloud platform application development in $1+\mathrm{X}$ certificate and industry top certificate, the project teaching content is integrated and designed by docking the core work "cloud platform development" and the core post "cloud computing engineer" of cloud computing enterprises, and the teaching is carried out by the double qualified teaching team to complete the development of face recognition. 


\section{Method of Ideological and Political Integration of Artificial Intelligence Course}

In order to cultivate high-quality cloud computing technical talents in line with the needs of the industry and enterprises, and make the teaching process of vocational colleges connect with the production process of enterprises, the course adopts the task-based teaching mode oriented to the real cloud computing environment of enterprises, and is taught by the cloud computing double qualification innovative teaching team. The team takes learners as the center to implement teaching, uses national planning textbooks, develops loose leaf handouts, connects the contents of $1+\mathrm{X}$ certificate and Huawei, red hat and other top industry certificates, and explores and practices the teaching implementation path of cloud computing course certificate integration under the background of national vocational education reform and implementation according to the characteristics and cognitive rules of higher vocational students.

At present, novel coronavirus pneumonia is still grim at home and abroad. In order to fully support and win the epidemic prevention and control war, we should build a course of ideological and political education in the higher vocational schools during the war epidemic with the same heart and mind, and carry out the task of "stopping classes and ceasing teaching and stopping classes without stopping learning". Guided by ideological and political education, "face recognition-wearing face mask for you" covers the original knowledge and skills of face recognition, adds ideological and political points, recognizes the face in the picture, and writes programs to realize the automatic wearing of face mask, so as to master the recognition of facial features, face data collection, recognition model training, and face mask program development, We should understand the importance of masks in the process of epidemic prevention and control, improve the awareness of epidemic prevention and control, and win the key war without gunpowder.

The teaching team takes two international standards of cloud computing, ISO/IEC, overview and vocabulary of information technology cloud computing, which are promoted by China, and ISO/IEC reference framework for it cloud computing as standards, and references national planning textbook "cloud computing application development technology course" and higher vocational $1+\mathrm{X}$ certificate textbook and self-developed new type loose page handout, Combining the talent training plan and the deployment and application development content of cloud platform in $1+\mathrm{X}$ certificate and top certificate of the industry, the core work of cloud computing enterprises "deployment and development of cloud platform" and "cloud computing engineer" are connected, and the project teaching content is integrated and designed to create a teaching project of "cloud platform deployment and cloud monitoring application development". As the core project of cloud application development, the core course of cloud computing, the project is taught by the two teacher teaching team, and the deployment of enterprise cloud platform and the development of artificial intelligence application monitoring system on cloud are completed, totaling 16 class hours.

Combined with the talent training program, the knowledge, ability and quality objectives of "face recognition-wearing masks for you" teaching unit are determined. The knowledge goal is to master the compilation of face recognition scheme, the ability goal is to master the ability of face recognition development, and the quality goal is to improve the awareness of epidemic prevention and anti-epidemic.

The teaching unit of "face recognition-wearing masks for you" is designed as a typical case of Ideological and political education in "war epidemic classroom". The teaching object is the third year students majoring in cloud computing technology and application. They have mastered the basic knowledge of cloud computing and development, can install, operate and manage Linux system, and hope to learn practical professional knowledge that meets the needs of enterprises.

The teaching unit of "face recognition putting on masks for you" consists of online learning platform of "integration of theory and practice", training platform and offline cloud computer room, which provides a real engineering environment of "learning implementation evaluation" with learners as the main body.

"Face recognition - putting on a mask for you" is the 15th class hour in the 16 class hour teaching unit "cloud platform deployment and cloud monitoring application development", which belongs to the practical teaching part of artificial intelligence application development and completes the practical teaching of face recognition.

In the last class hour, students learned the realization of deep learning model of target detection. This class hour "face recognition-wearing a mask for you" is mainly about how to use deep learning to solve the task of face recognition. Face recognition is an important part of cloud monitoring applications.

The teaching emphasis of "face recognition—putting on a mask for you" teaching unit is to make face recognition model scheme.

(1) Pre-class grouping scheme: before class, students browse the national teaching resources database, watch micro class, prepare face recognition model scheme, submit reports in groups and upload them to the learning platform for self-evaluation, mutual evaluation and teacher evaluation.

(2) Group display and comments: student's group display face recognition design scheme, teachers comment, and put 
forward modification suggestions.

(3) Group PK verification scheme: students realize face recognition in the form of group PK to verify the correctness of the scheme method.

Through the above three steps, students can master the key point of teaching-making face recognition model scheme.

The difficulty of the teaching unit of "face recognition—putting on a mask for you" is to make a face recognition model scheme.

(1) Learning knowledge before class: students browse the national teaching resources database and watch micro class before class to learn the knowledge needed to realize the task of face recognition, and understand the mastery degree of face recognition related knowledge by completing the quiz of the learning platform.

(2) Group display and comment: students in the class group display face recognition model scheme, teachers' comments, and put forward modification suggestions.

(3) Teacher practice demonstration, student group PK: the key steps and error prone steps of teacher practice demonstration face recognition, students realize face recognition task in the form of group PK.

(4) Multiple evaluation: the training platform draws learners' big data portraits according to the learning and training situation. On the basis of system intelligence evaluation, combined with self-evaluation, mutual evaluation, teacher evaluation and enterprise evaluation, it conducts multiple evaluation on the face recognition results made by students.

Through the above four steps, students break through the teaching difficulty-face recognition task.

The COVID-19 affects every citizen's heart. In the face of this war without smoke of gunpowder, it is with firm faith that countless white soldiers can face the virus and defeat it without fear of difficulties and dangers!

Under the guidance of classroom ideological and political education, students investigate the various deeds of medical workers in fighting against the epidemic, deeply understand the firm belief of excellent medical workers, and investigate the importance of masks in epidemic prevention and anti-epidemic group. At the same time, learn how to build face recognition model, and recognize their beautiful faces in the photos of medical workers.

(1) Ideological and political education before class: students investigate and study the various deeds of medical workers in fighting against the epidemic situation in groups before class, and discuss how to identify the beautiful faces of medical workers in the images, investigate the importance of masks in epidemic prevention and anti-epidemic in groups, and complete the report according to the investigation.

(2) Ideological and political education in class: students discuss in groups how to complete the task of face recognition on the image, recognize the face in the image, write a program to realize the automatic wearing of face mask, so as to master the ability of recognizing facial features, face data collection, recognition model training, and the development of face mask program, And lead students to learn face recognition task implementation and test results.

(3) After class ideological and Political Education: after class, students discuss how to improve the task of face recognition and apply it to the video, recognize the faces of TCM nursing workers in the video, participate in community epidemic prevention work in groups, and make epidemic prevention posters, so as to contribute to winning the key war without gunpowder smoke.

"Face recognition-put on the mask for you" teaching unit adopts the teaching form of learning by doing and teaching by doing. It achieves the goal of knowledge-Mastering the compilation of face recognition scheme through three links: Group preparation of face recognition scheme before class, group display, discussion and comment in class, and group PK verification scheme; Through watching micro class before class, group discussion and comment during class, teacher's practical demonstration, student's group PK and multiple evaluation, we can achieve the ability goal of mastering the ability of face recognition development; The importance of face masks in epidemic prevention was investigated by students in groups before class. In class, face masks were automatically worn by recognizing faces in pictures and writing programs. After class, they were divided into groups to participate in community epidemic prevention work and make epidemic prevention posters to achieve the quality goal of improving the awareness of epidemic prevention.

According to the analysis of the teaching evaluation results before, during and after class, through the three stages of learning, the students' mastery of face recognition task is significantly improved.

Face recognition is an important part of cloud monitoring applications. According to the multiple evaluation found that the teaching of this course to achieve the goal of knowledge, ability and quality goals, students grasp the teaching focus, break through the teaching difficulties.

\section{Conclusion}

The novel coronavirus pneumonia is a new teaching method for face recognition. This is a case of "face recognition for you to wear masks". In order to guide the class in politics, we take the new crown pneumonia epidemic situation as 
the breakthrough point at home and abroad, and recognize the faces in the picture, and program the program to automatically mask the face, so as to master the development ability of facial features recognition, face data acquisition, recognition model training, and face mask procedure. We should understand the importance of masks in the process of epidemic prevention and control, improve the awareness of epidemic prevention and control, and win the key war without gunpowder.

The main innovation of the teaching case of "face recognition-wearing a mask for you" lies in: classroom ideological and political guidance, throughout the whole teaching process. Under the guidance of Ideological and political education in the classroom, students understand the firm belief through understanding the anti-epidemic deeds of the most beautiful rebels and medical workers in white. Before class, students are divided into groups to investigate and study the various deeds of medical workers in fighting against the epidemic situation, and discuss how to identify the beautiful faces of medical workers in the images, and investigate the importance of masks in epidemic prevention and anti-epidemic, and complete the report according to the investigation. Students in the class are divided into groups to discuss how to complete the task of face recognition on the image. By recognizing the face in the image and writing a program to realize the automatic wearing of face mask, they can master the ability of recognizing face features, collecting face data, training face recognition model and developing face mask program. The teacher comments and summarizes, and leads the students to learn the realization of face recognition task and test the results. After class, the students discuss how to improve the face recognition task and apply it to the video, recognize the faces of TCM nursing workers in the video, participate in community epidemic prevention work in groups, and make epidemic prevention posters, so as to contribute to winning the key war without gunpowder smoke.

In the interaction between teachers and students in one teacher's life and one space, students recognize the face recognition technology very much, and hope to try to use the face recognition technology on the existing domestic cloud platform for application development. According to the feedback of students, the diagnosis and correction scheme is formulated, and the face recognition service content of Huawei Kunpeng modelarts is added for students to learn.

\section{Acknowledgement}

This work is supported by Education Science Planning Project of Guangdong Province in 2021 (No. DSYJ108).

\section{References}

Ali, F. (2020). The Origins of Contemporary Moral Education and Political Ideology in Confucian-Marxist H Chí Minh’s Vietnam. Asian Studies, 8(2): 115-134.

Chi, Wai, Chan. (2019). Moral education in Hong Kong kindergartens: An analysis of the preschool curriculum guides. Global Studies of Childhood, 10(2): 156-169.

Liu, Xinwei. (2019). Moral Education, Legal Practice-Exclusive Interview with Lu Jianping, Dean of BNU Law School. China's Foreign Trade, No. 573(03): 30-33.

Lu, X. and Xunzi. (2020). Moral education and transformation. Asian Philosophy, 1-11.

Mapana, K. E. (2020). Why the Enculturative Context of Moral Education Matters: Values among the Wagogo People of Central Tanzania through an Auto-Ethnographic Perspective. Utafiti, 15(1): 28-44.

Mukhlas, M. and Fajriani, N. S. (2020). The Implementation of Moral Education With Methodology of Remembrance, Thought and Compassion at Dar al Hikmah Islamic Boarding School Mlarak Ponorogo. Educan Jurnal Pendidikan Islam, 4(1): 12.

Park, Y. J., Noh, H. J., and Jeong, W. Y. (2020). A Study on the Field Application of the Link Between Cross-curricular Themes and Elementary Moral Education. Journal of Ethics Education Studies, 55: 139-163.

The, K. and Zulafiat. (2019). Value and Moral Education Approach of Ka Seto Homeschooling in Jakarta, Indonesia. Journal of Legal, Ethical and Regulatory Issues, vol. 22.

Yan, S. and Slattery, P. (2021). The Fearful Ethical Subject: On the Fear for the Other, Moral Education, and Levinas in the Pandemic. Studies in Philosophy and Education, 40(4): 1-12.

Zybaa, A. (2021). On Moral Education in Poland against the Background of Anglo-Saxon Experiences and Tendencies. Edukacja, 2020(1): 21-41. 